\title{
Towards Sustainable Public Open Spaces for Promoting Human Comfort, Health and Well-Being: The Case of Oxygen Park in Doha, Qatar
}

\author{
Eman Al-Fadala \\ 200558264@student.qu.edu.qa \\ Architecture and Urban Planning Department, Qatar University, Doha, Qatar \\ Fodil Fadli \\ f.fadli@qu.edu.qa \\ Architecture and Urban Planning Department, Qatar University, Doha, Qatar
}

\begin{abstract}
Public Open Spaces (POS) are an important and necessary component of the urban city design. Well-designed and well-functioning public open spaces provide a variety of social, economic, environmental, physical and psychological advantages for populations, and thus play a substantial role in improving the quality of city life and contributing to livability. Doha city, the capital State of Qatar, has encountered a rapid urbanization which brought with it an increasing number of inhabitants and the implementation of many urban projects (Salama \& Wiedman, 2013); these changes demand well-designed and well-functioning public open spaces. Responding to this need, this paper aims to develop design guidelines for a sustainable public open space by exploring the physical and non-physical characteristics of a few key public open spaces as well as the ways in which environmental conditions impact user comfort, health and well-being-with an eye for accessibility, sociability, activities and user's comfort - in these POS. To achieve this aim, a combined methodology based on quantitative and qualitative techniques was developed and used to encompass the multi-dimensionality of the POS. Expected outcomes state that POS can become catalyst for healthy urban spaces if a series of multi-dimensional parameters are considered at all design stages.
\end{abstract}

Keywords: Sustainable urban development (SUD); Public open spaces (POS); Sustainable city design; Oxygen park

\section{INTRODUCTION}

Qatar has recognized the need to concentrate on Sustainable Urban Development (SUD) goals expressed through developing sustainable cities. SUD directives significantly focus on treating factors that affect human comfort, health and well-being. Research has shown that Public Open Spaces (POS) are a necessary component of urban city design (Habitat, 2014). Well-designed and well-functioning POS, provide a variety of social, economic, environmental, physical and psychological advantages for populations, and thus play a substantial role in improving the quality of city life and contributing to livability.

Cities worldwide are becoming larger, more complicated as the urban areas experiencing rapid urban growth and the increase in the population. This accelerated change, in turn, has led to emergence problems related to the urban design qualities of POS. Most POS are rather uncomfortable because they were not designed to adapt to 
different environmental conditions.

Oxygen Park is considered a new POS developed for serving as an outdoor green oasis in education city that invited the students of the QF and the general public to refresh their bodies, minds and emotions by walking, engaging in sports and discovering the symbiotic relationships between plants, oxygen and healthy living. Thus, the aim of this study is to develop a set of design guidelines for sustainable POS to ensure that Doha POS promote comfort, health and well-being and, in turn, achieve SUD. The main objectives are to assess the physical and non-physical characteristics of these POS and examine how environmental parameters impact user comfort.

In order to do so, an evaluation criteria framework has been developed. Accordingly, combined methodologies were adopted to realize the main aim. More specifically, this study used both quantitative and qualitative techniques to encompass the multidimensionality of the POS. These approaches are rooted in the four aspects of a sustainable POS, namely: accessibility, sociability, activity, and user comfort, that is, the evaluation criteria, in order to then proceed to evaluate the abilities of Oxygen park and their impact on users' comfort, health and well-being.

The outcomes outline that the major physical factor of Oxygen park influencing is user comfort. Furthermore, the findings reveal that comprehending the mutual relations among environmental conditions and psychological adaptation factors may prove significant for evaluating the design qualities of POS. Notably, the study found that the microclimate, noise level and air quality significantly affected psychological adaptation, user comfort and health.

\section{PUBLIC OPEN SPACES AND USER COMFORT, HEALTH AND WELL- BEING}

Public Open Spaces (POS) is any land open into outdoor space which is accessible by all and it includes parks, plazas, squares, etc. where these spaces are normally publicly owned and can be used by all on daily basis for various activities (Nochian, Tahir, Maulan \& Rakhshanderoo, 2015). The term 'comfort' is synonymous with 'well-being' and defined as 'the immediate state of being strengthened through catering the needs for relief, ease, and transcendence addressed in the four contexts of comprehensive human experience: sociocultural, environmental, physical, and psycho-spiritual' (Kolcaba, 2003). Meanwhile, 'health', as defined by the World Health Organization (WHO), signifies 'a state of complete physical, mental and social well-being and not merely the absence of disease or infirmity' (WHO, 1948). Comparatively, 'well-being' signifies 'the presence of positive emotions and effects (e.g. happiness), the absence of negative emotions (e.g. anxiety), and satisfaction with life' (Pintoa, Fumincellic, Mazzoc, Caldeirad \& Martins, 2017).

In this context, POS yields socio-cultural, environmental, physical psychological benefits by enhancing social interaction (socio-cultural well-being), fostering physical activity (physical well-being) and enhancing relaxation and reducing stress (psychological mental well-being). Furthermore, POS have a great political and economic significance, and the degree to which any town has livable open grounds is a depiction of civilization (Brook, 2014). Several advantages accrue to an urban settlement with POS within the built environment. The most common benefits relate to health and wellbeing, tolerance, 
learning, and economic. POS grounds can provide health gains as they act as arenas for inhabitants and employees to enjoy fresh air, lessen sedentary lifestyle, and exercise. Thus, open places are significant for residents' physical and mental health. Such spaces can further give social learning openings. They aid people to directly meet other people with different cultures and lifestyles. Thus, it is important to ensure that POS is accommodating the sustainable aspects.

\subsection{Aspects of Sustainable Public Open Spaces}

There are four aspects of an efficient POS which incorporate creative activities and stimulate use such as those that of accessibility, sociability, activities and user comfort (Ageing, 2009). The following Table 1 show these aspects as evaluation criteria that have used for the identified POS.

Table 1: Aspects of Sustainable POS

\begin{tabular}{|l|l|l|}
\hline 1 & Accessibility & $\begin{array}{l}\text { - Integrated diverse land with transportation systems. } \\
\text { - Good signage system. } \\
\text { - Space visually connected with adjacent buildings. } \\
\text { - Equal access for all people. }\end{array}$ \\
\hline $\mathbf{2}$ & Sociability & $\begin{array}{l}\text { - Accessible for everyone. } \\
\text { - High proportion of users in groups. } \\
\text { - Emphasizing local identity. } \\
\text { - People meet and see friends. } \\
\text { - Feeling comfortable speaking with strangers. }\end{array}$ \\
\hline $\mathbf{3}$ & Activities & $\begin{array}{l}\text {-Lively, attractive environment for visitors. } \\
\text { - Utilized by everyone (high proportion of users in groups). } \\
\text { - Recreational places that activate the space and enable diverse } \\
\text { activities. }\end{array}$ \\
\hline $\mathbf{4}$ & $\begin{array}{l}\text { - Meeting expectations to satisfy user groups. } \\
\text { - Safety: by installing lighting oriented towards faces, CCTV and } \\
\text { security personals. } \\
\text { - Provision of places to sit. } \\
\text { - Air temperature, humidity and wind. } \\
\text { - Noise and air quality. }\end{array}$ \\
\hline
\end{tabular}

\subsection{Physical Public Open Spaces Characteristics}

POS physical characteristics can be studied through usage and perception. The framework of the identified physical elements of a POS includes vegetation, water features, lighting and safety, urban furniture, general bins, signage, and floorscapes (Madanipour, 1996). Meanwhile, a questionnaire can be used to determine users' perceptions of particular elements and their influence.

\subsection{Non-Physical Public Open Spaces Characteristics}

Psychological variables affect user perceptions of comfort. There are five variables constitute the framework for evaluation, namely: environmental stimulation, time of exposure, perceived control, naturalness of the space and expectations and experience (Nikolopoulou \& Steemers, 2003). 


\subsection{Environmental Conditions Impacting User Comfort}

Microclimatic conditions refer to the sets of atmospheric elements that connect the climate of metropolitan areas and civil activities (BojinSki \& VerStraete, 2014). Relative humidity, air temperature, and wind velocity are variables of the microclimate that have focused on this study. In other respect, noise is an important public environmental problem. It signifies undesirable sounds in outdoor environments that negatively impact human comfort. A noise level is measured by decibels (dB) (Table 2) (Audiology, 2009).

Table 2: Level of Noise in Decibels (Audiology, 2009)

\begin{tabular}{|c|c|c|c|c|c|c|c|c|}
\hline Category & Faint & Soft & Moderate & Loud & \multirow{2}{*}{$\begin{array}{c}\text { Over } 85 \mathrm{~dB} \\
\text { for long }\end{array}$} & Very loud & Uncomfortable & $\begin{array}{c}\text { Painful and } \\
\text { dangerous }\end{array}$ \\
\cline { 1 - 1 } Decibel & 20 & $30-40$ & $50-60$ & $70-80$ & $\begin{array}{c}\text { period can } \\
\text { cause loss }\end{array}$ & $90-100-110$ & $\begin{array}{c}120 \text { (Dangerous } \\
\text { over } 30 \\
\text { seconds) }\end{array}$ & $130-140$ \\
\hline
\end{tabular}

Meanwhile, air quality refers to the condition of the air and the degree to which it is free from harmful pollutants that impact human health and generate many environmental problems (Lanzafamea, Monfortea, Patanèa \& Stranoa, 2015). Due to the emergence of several environmental problems, in 1999, the Environmental Protection Agency (EPA) developed the Air Quality Index (AQI) to estimate and monitor the overall state of the level of air pollution and human health (EPA, 1999) (Table 3). This index enables daily reports of air quality by measuring the concentrations of pollutants in urban areas and showing their associated health effects.

Table 3: Air Quality Index (EPA, 1999)

\begin{tabular}{|c|c|l|}
\hline $\begin{array}{c}\text { Levels of Health } \\
\text { Concern }\end{array}$ & AQI Values & \multicolumn{1}{c|}{ Colors and Meaning } \\
\hline Good & 0 to 50 & Air quality is good. \\
\hline Moderate & 51 to 100 & Air quality is acceptable; a moderate health concern may exist. \\
\hline $\begin{array}{c}\text { Unhealthy for } \\
\text { Sensitive Groups }\end{array}$ & 101 to 150 & $\begin{array}{l}\text { The public is not likely to be affected; sensitive people may } \\
\text { experience health effects. }\end{array}$ \\
\hline Unhealthy & 151 to 200 & Every person may start to experience some harmful health effects. \\
\hline Very Unhealthy & 201 to 300 & Every person may experience serious health effects (health alert). \\
\hline Hazardous & 301 to 500 & This is an emergency condition that demands health warnings. \\
\hline
\end{tabular}

\section{STUDY METHODS, STAGES AND TOOLS}

The study explores the POS of Oxygen Park through a particular focus on studying the POS design qualities to understand how their design provides sustainable POS aspects and which in turn promoting comfort, health, and well-being. To fulfil this aim, the overall research methods has adopted three steps (Fig. 1):

(1) Determination of the aspects of a sustainable POS directing the Oxygen Park through a review of the literature and research studies; (2) The quantitative method has been used to produce objective measurements that are fundamentally utilized to measure POS microclimatic variables, noise and air quality. This method helps to comprehend the overall environmental conditions, which are important in determining how to realize external psychological adaption and user comfort. Further, on-site measurements were done by using data devices. The Multifunction Environment Meter (CEM DT-8820) 
utilized for air temperature, humidity and sound. The Kestrel 4500 (Pocket Weather Tracker), utilized for measuring wind velocity. The iPhone, fitted with an application called the Airvisual App (IQAir), which measured the air quality. Measurements were done on weekdays and weekends, from 8 am to $9 \mathrm{pm}$ and logged every hour; (3) Qualitative method has been used to produce subjective measurements of a real-time situation. The authors carried out several site visits to understand the studied POS and the physical design elements. Furthermore, these measurements are conducted in order to obtain a better understanding of the design aspects of POS, comfort levels, perceptions, and human behavior. Hence, the main techniques were a questionnaire and observation.

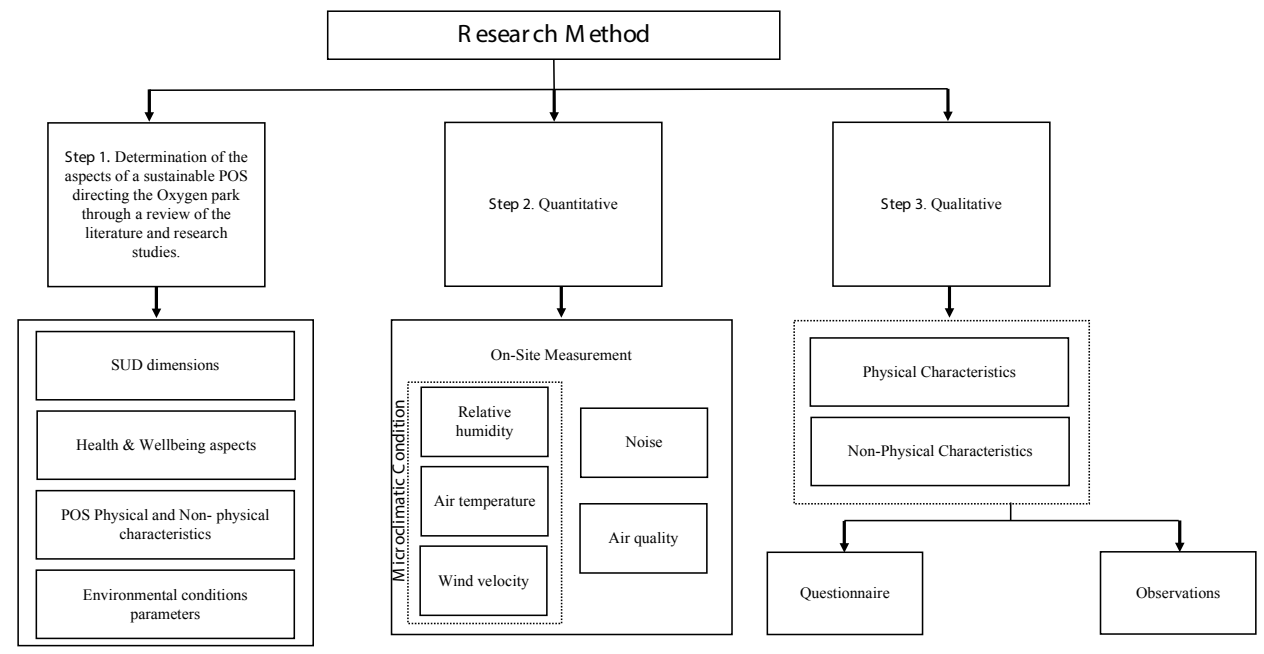

Figure 1: Research Method Used for This Study

\section{OXYGEN PARK}

\subsection{Overview of the Study Area}

Oxygen Park is considered a newly developed park in the Al Rayyan area (Fig. 2), and located within the boundaries of education city, where it was implemented by the Qatar Foundation (QF). The POS of Oxygen Park opened in the 2016 and occupied 130,000 $\mathrm{m} 2$ with the aim of serving as an outdoor green oasis in education city that invited the QF students and the general public to refresh their bodies, minds and emotions. The Park is accessible to people of all ages and is connected by Huwar Street, and Al Huqoual Street. Currently, the POS of Oxygen Park has no gates, or fences; it can thus be accessed from everywhere. Oxygen Park is divided into two zones. The first zone was allocated for sports constitutes two levels: upper and lower and the second for recreation (Fig. 3). 


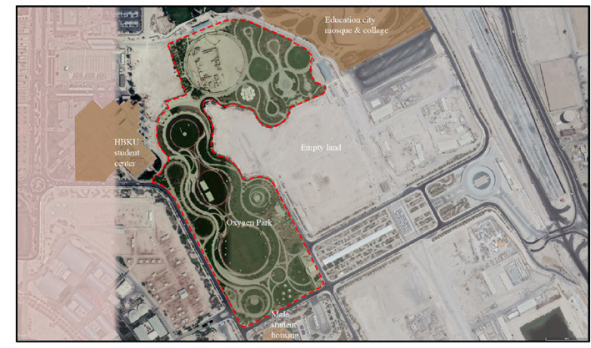

Figure 2: The Location Map of Oxygen Park

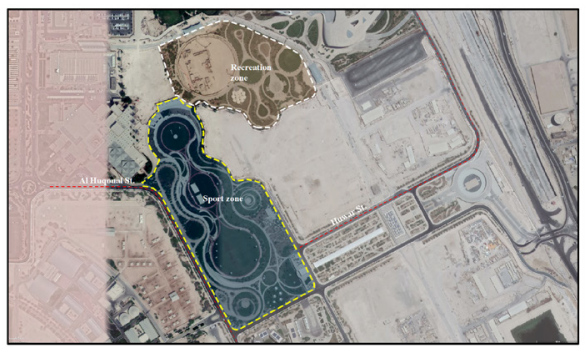

Figure 3: The Zones Map of Oxygen Park

\subsection{POS Physical Characteristics Assessment}

Oxygen Park, demonstrated some of the physical characteristics and elements, discussed in the literature review. The existing physical elements and related observations are as follows:

- $\quad$ Oxygen park has a variety of native plants, trees, shrubs and grass banks (Fig. 4).

- In terms of water features, over the edge of the pathway covering there are cascading waterfalls, which offer a beautiful sight, sound and water spray (Fig. 5).

- The lighting system is plentiful in different zones throughout the park (Fig. 6). There is spotlighting, column and 14 big lighting poles that provide better illumination at night. The park is also equipped with surveillance equipment such as CCTV and security personals.

- The lower level involves seats in sun and in shade. The upper level also provides seats for all users (Fig. 7). Further, there is amphitheater with grassy banks that provide space to gather, sit and see the sporting activities. Additionally, the park is equipped with trash and recycling bins (Fig. 8).

- $\quad$ The Oxygen park has a good signage system inside the park (Fig. 9).

- The surface of the ground in Oxygen Park is of a mixture of artificial hills and flat land. It has light concrete pavement, soft walking mats (rubber) and sand trails.

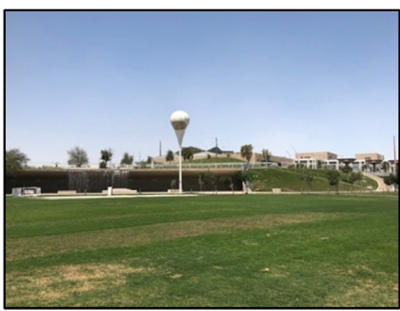

Figure 4: Vegetation

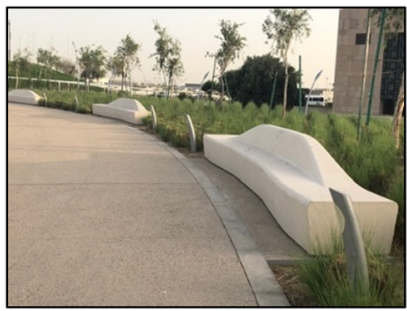

Figure 7: Seats

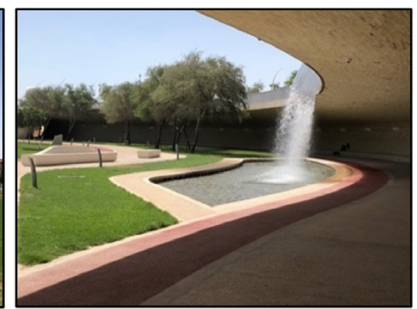

Figure 5: Water Feature

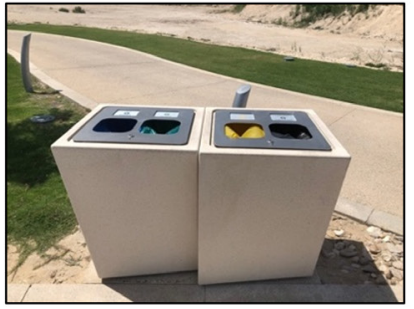

Figure 8: Recycle Bins

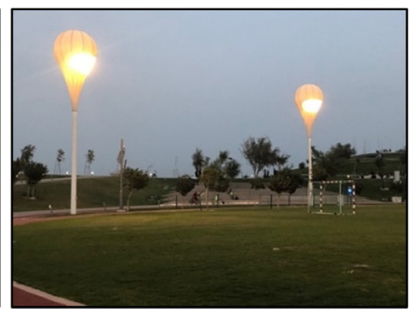

Figure 6: Lightings

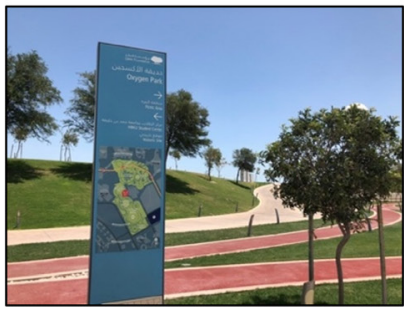

Figure 9: Signage 


\subsection{POS Non-Physical Characteristics Assessment \\ 4.3.1 User Physical Well-Being: Activities}

Both social and optional activities were observed. Users were found sitting on the green hills enjoying their time and relaxing, or walking around the POS. There is a certain spot very attractive to adults and children: the circular multi-use sports courts, which is offer a running path and pitches.

\subsubsection{User Psychological Well-Being: Psychological Adaptation}

On day 1: questionnaire assessment (24-04-2019) —weekday: during the morning from ( $8 \mathrm{am}$ to $11 \mathrm{am}$ ), based on the survey results, $100 \%$ of users did not desire any change in the humidity level or wind velocity (Fig. 10). However, 33\% of users were not satisfied with air temperature at $(9 \mathrm{am})$. Between $(4 \mathrm{pm}$ and $5 \mathrm{pm})$, the users began to endure overall weather conditions. During the evening period, from (6pm to $8 \mathrm{pm})$, users were able of enduring general weather condition. It is important to note that at $(1 \mathrm{pm}$, 2pm and $9 \mathrm{pm}$ ), no users filled out the survey; this gap is evident in the graph. While on day 2: (27-04-2019)-weekend: from (10am to 12pm), users were unable to endure the weather conditions. Over the afternoon, at (1 pm and $3 \mathrm{pm})$, all users preferred low air temperature with low humidity, with $75 \%$ not pleased with the wind velocity. Time from $(6 \mathrm{pm}$ to $9 \mathrm{pm})$, the results show that users desired no changes into air temperature, humidity and wind velocity (Fig. 11).

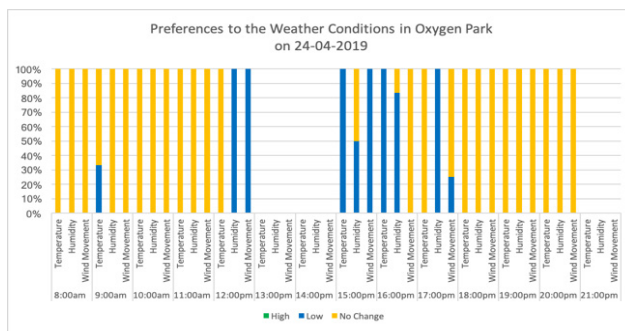

Figure 10: Preferences to Weather Conditions on 24-04-2019

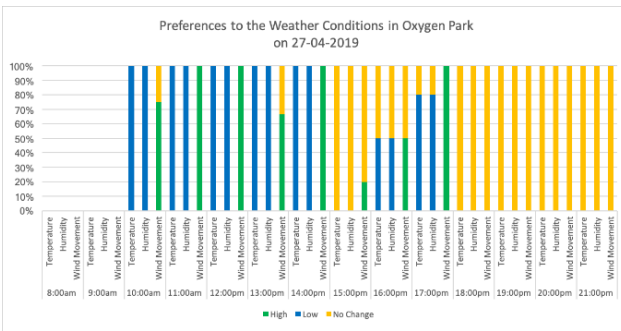

Figure 11: Preferences to Weather Conditions on 27-04-2019

Regarding duration of stay, $23.53 \%$ of visitors were able to stay in the POS for over an hour on weekday. It is significant to note that, on this day, there was a total of 34 visitors surveyed. While on weekday, 41 users in total were surveyed in the park.

Environmental stimulation is a unique feature that distinguishes this space. These features are evident in the beautiful landscape, the sound of the waterfall, and the greenery that encourage people to visit the POS. Furthermore, on weekday, it was observed that individuals and groups used the park between ( $8 \mathrm{am}$ and $3 \mathrm{pm}$ ); individuals, groups, and families frequented it between ( $4 \mathrm{pm}$ and $8 \mathrm{pm})$ and families constituted the highest percentage of visitors after $(6 \mathrm{pm})$. While on the weekday during the time between (10am and $12 \mathrm{pm}$ ), it was noticed that the POS was occupied more by individuals. In contrast, between (3pm and 9pm), the park was primarily used by individuals and groups, including a few families. 


\subsection{Environmental Conditions Assessment}

Day 1: microclimate condition (24-04-2019): the hottest peak was recorded during the afternoon period at $3 \mathrm{pm}$ at $26^{\circ} \mathrm{C}$, whereas, the humidity was found at one of its lowest levels at $25 \%$ and wind velocity was one of the highest recorded readings at $25.9 \mathrm{~km} / \mathrm{h}$ (Fig.12). In other respect, the coolest peak was at $8 \mathrm{pm}$ at $22^{\circ} \mathrm{C}$ with one of the highest humidity levels at $33 \%$ and the highest wind velocity at $25.2 \mathrm{~km} / \mathrm{h}$. Based on these readings, the sum temperature reached $17^{\circ} \mathrm{C}$ as per the outdoor comfort online calculator. For the day 2 (27-04-2019): the hottest peak was logged in between (1pm and $3 \mathrm{pm}$ ), with $29^{\circ} \mathrm{C}$, during which time low humidity was logged at $21 \%$ and moderate wind velocity was recorded at $21.6 \mathrm{~km} / \mathrm{h}$ (Fig 13). Accordingly, the sum temperature reached $23^{\circ} \mathrm{C}$.
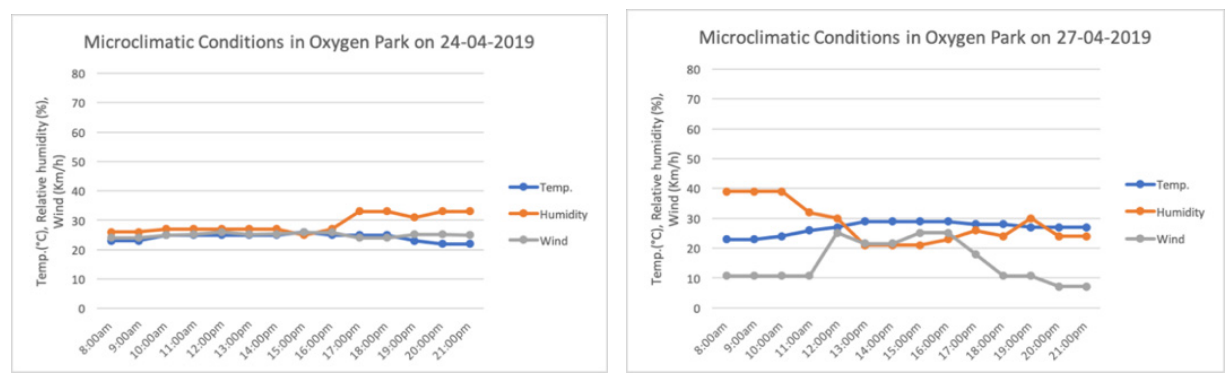

Figure 12: Microclimate Condition (24-04-2019) Figure 13: Microclimate Condition (27-04-2019)

On the other hand, the noise level readings on (24-04-2019) demonstrate that the highest sound level occurred between ( $5 \mathrm{pm}$ and $7 \mathrm{pm}$ ) at $74 \mathrm{~dB}$ (Fig. 14). Comparatively, the noise was low at $(2 \mathrm{pm})$ at $35 \mathrm{~dB}$ (soft). Meanwhile, day 2: (27-04-2019): the noise level was between $30-40 \mathrm{~dB}$ and $50-60 \mathrm{~dB}$. The high sound level was logged in the morning (9am) and (10am) at 56dB (Fig.15).

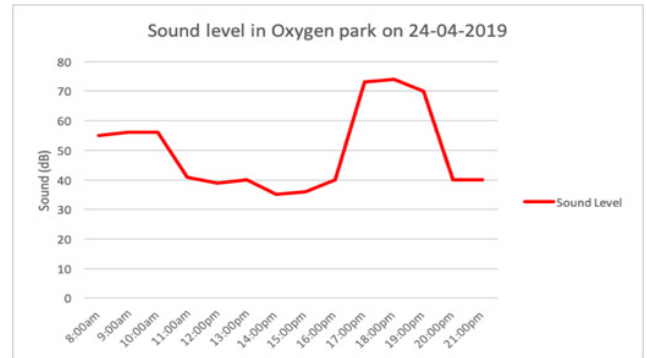

Figure 14: Sound level on 24-04-2019

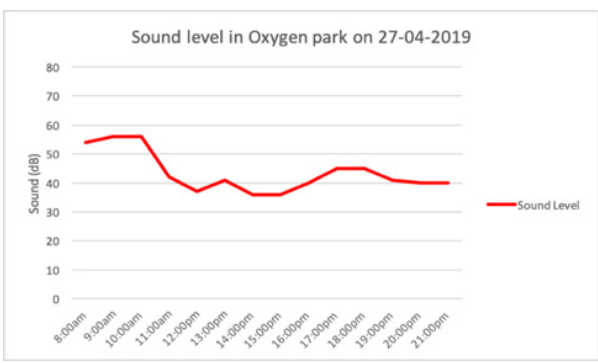

Figure 15: Sound level on 27-04-2019

The air quality readings of weekday were in an AQI range between 51-100 (yellow), signifies that the air quality was 'moderate' and acceptable (Fig. 16). Whereas, the air quality readings on weekend were between 101-150, that is, 'unhealthy air for sensitive groups' (Fig. 17). 


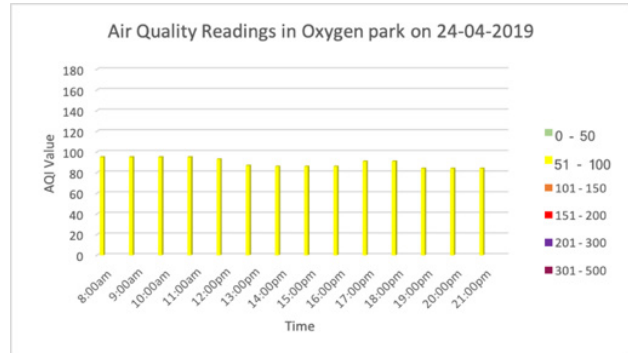

Figure 16: Air quality on 24-04-2019

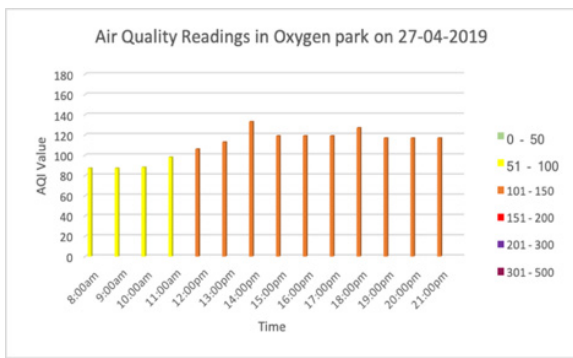

Figure 17: Air quality on 27-04-2019

\section{CONCLUSION}

POS are essential ingredients of SUD and healthy cities. In this paper, it has been reviewed the POS Of Oxygen park-by unpacking three factors (physical, nonphysical characteristics and environmental conditions) to deepen existing knowledge about sustainable specification. The findings affirmed that Oxygen Park relies on the promoting of the user comfort, health and well-being through sustainable urban design qualities. The study also confirmed that the physical characteristics significantly impact the comfort level experienced. In addition, the study assured the need to highlight the importance of non-physical characteristics that impact user psychological adaptation and comfort. According to the data of POS that have been obtained supported the conclusions of this study and its development of design guidelines for Doha's POS. These guidelines can be summarized as follows: (1) different types of vegetation and trees should be introduced; (2) Water features are beneficial and should be provided in all sorts of forms; (3) Lighting and safety elements should be provided; (4) Adequate furniture should be available throughout the space; and (5) Signage should be readable and well distributed. Through consideration, all of that POS can promote user comfort and well-being.

\section{REFERENCES}

Ageing, A. G. D. o. H. a. (2009). Health Spaces \& places: a national guide to designing places for healthy living. Retrieved from Planning Institute of Australia: https://www.healthyplaces. org.au/userfiles/file/HS\&P\%20An\%20overview.pdf

Audiology, A. A. O. (2009). Level of noise in decibel. In: American Academy of Audiology.

Brook, D. A. (2014). History of Future Cities. New York: W. W. Norton \& Company.

BojinSki, S. \& VerStraete, M. (2014). The concept of essential climate variables in support of climate research, applications, and policy, (vol. 95): Bulletin of american meteorological society.

EPA. (1999). Guideline for reporting of daily air quality - air quality index (AQI). In. Office of Air Quality Planning and Standards: Research Triangle Park, NC 27711.

Habitat, U. N. (2014). Public Space in the Global Agenda for Sustainable Urban Development. Retrieved from Nairobi GPO Kenya: www.unhabitat.org

Kolcaba, K. (2003). Comfort theory and practice: a vision for holistic health care and research. Ottawa: Springer Publishing Company.

Lanzafamea, R., Monfortea, P., Patanèa, G. \& Stranoa, S. (2015). Trend analysis of Air Quality 
Index in Catania from 2010 to 2014. ATI 2015 - 70th Conference of the ATI Engineering Association, Energy Procedia, 2015(82), 708-715.

Madanipour, A. (1996). Design of Urban Space. In. London: Wiley.

Nochian, A., Tahir, O., Maulan, S. \& Rakhshanderoo, M. (2015). A comprehensive public open space categorization using classification system for sustainable development of public open spaces. In (Vol. 8). Serdang: Universiti Putra Malaysia.

Nikolopoulou, M. \& Steemers, K. (2003). Thermal comfort and psychological adaptation as a guide for designing urban spaces. Energy and Buildings, 95-101.

Pintoa, S., Fumincellic, L., Mazzoc, A., Caldeirad, S. \& Martins, J. (2017). Comfort, well-being and quality of life: Discussion of the differences and similarities among the concepts. 2(1), 6-12.

Salama, A. \& Wiedman, F. (2013). Demystifying Doha. London, UK: Ashgate Publishing Limited.

WHO. (1948). WHO definition of health (online). Retrieved from https://www.who.int/ governance/eb/who_constitution_en.pdf 